\title{
Developing a new monitoring mechanism of electronic document management of technical documentation for railway automation
}

\author{
Dilshod Baratov* and Elmurod Astanaliev \\ Tashkent State Transport University, Tashkent, Uzbekistan
}

\begin{abstract}
The methods of creating automation tools in the general and analytical process and improving their efficiency are carried out in terms of brief comments on construction and creation and improving their efficiency. Electronic record keeping systems are considered. The creation of automated electronic document management systems and a comparative analysis of these processes are presented. Methods of analysis, synthesis and study of technical documentation electronic document flow are formalized. A graphical model of the electronic document management of technical documents is synthesized. The developed model considers the division of document flows into a set of participants, processes and situations. It is recommended to use a set of matrices to determine the form of presentation of the workflow of technical documentation. Based on the apparatus of graph theory, a method of creating an electronic document management model of technical documents are developed.
\end{abstract}

\section{Introduction}

The problems of registration of electronic document flow in the technical documentation in the works are considered [2-9]. However, the task of clearly formalizing the concept of "electronic document management of technical documentation" and using it in the railway and the use of existing advances in information technology to solve problems of document circulation remain relevant.

This article describes a new approach to creating workflow types of device-based technical documentation of graphic theory. Methods of defining position to the developed model are described, and flow of documentation algebra usage graphs is intended.

Formally, the electronic format of the technical documents process is represented as three finite sets and links of elements of these sets to each other. The mathematical notation of this process is represented as a triple.

$$
D_{T}=\{Y, P, F\}
$$

Where $D_{T}$ is official model of the electronic document management of technical documentation in the system; $Y$ is the sum of the participants; $P$ is the sum of these

*Corresponding author: baratovdx@yandex.ru 
processes; $F$ is the sum of TD cases with the correct range. The collection of $Y$ is defined as a limited set of actual participants in a workflow and a limited set of processes performed in a workflow system considered by participants in a P set. F is a limited set of cases with TD. Processes in set $\mathrm{P}$ can be completed by participants after set $\mathrm{Y}$.

When creating a graphical model of TD workflow, it is recommended to using the following method of representing TD workflow using graphs[10]. Use the number of possible F cases to determine the set of peaks in the graph. The graphic edges are set using a set of $\mathrm{P}$ processes and are set of $\mathrm{P}$ processes and are set according to the following rules:

- one graphic node corresponds to one and only one element of the base $F$;

- one graphic edge corresponds to one and only one element of the base $P$;

- one element of the base $F$ corresponds to one and only one vertex of the chart;

- one element of the base $P$ corresponds to one and only one edge of the chart.

A similar description of a basis of cases $F$ for a basis of vertices $v$ and a basis of processes $\mathrm{P}$ for a basis of edges $e$ can be mathematically defined as follows: for any $I$, this statement is true.

$$
v(i) \leftrightarrow F(i) \text { and } e(i) \leftrightarrow P(i)
$$

where $i \in I, I=1,2,3, \ldots, n$.

Thus, two pairs of sections were clarified - the first part to set the translation of $F$ to $V$ and the second part to base the translation of $P$ to $e$.

Therefore, the relationships between peaks are similar to the case relationship of the modelled workflow. Once the set of processes $P$ is implemented, the $F$ cases of the altering technical documentation. In a workflow graph, if the graphic vertices connect the edges to each other, that is, only if the corresponding vertices of the case are connected by a motion corresponding to the edge, i.e.

$$
e=\left\{\begin{array}{l}
e, \text { if the edge exists; } \\
0, \text { if the edge is missing }
\end{array}\right.
$$

The direction of the edges is base so that the logic of the sequence of changing workflow states is displayed. The vertex $I$ is the unwanted vertex for the vertex $\mathrm{j}$ through the $\mathrm{j}$ edge if the vertical $\mathrm{j}$ moves to the $\mathrm{j}$ position after moving. Thus, the cases $y_{1}, y_{2}, \ldots, \mathrm{y}_{\mathrm{n}}$ are plotted on the vertices of the graphs $v_{1}, v_{2}, \ldots, \mathrm{v}_{\mathrm{n}}$ and each $v_{i}$ and $v_{j}$ vertex pair is connected by the edge of $e_{i j}$ passing from $v_{i}$ to $v_{j}$, and only if the $v_{i}$ position is the input state for $v_{j}$.

To obtain a clear description of the various structural features of the workflow, it is useful to include in the graphical model several concepts that have been identified and widely used in graphic theory[11-14]. The non-empty $V$ set, the isolated $E$ set (possibly empty), and the $F$ map of the $E\left(V^{2}\right)$ set are graphics. The elements of set $V$ are the peaks, the elements of set $E$ are the edges of the graph, and $F$ is the plot of the graph.

\section{Methods}

DEFINITIONS OF A GRAPH-BASED WORKFLOW PROCESS.

For technical documents, the following format has been adopted to display the document flow diagram.

$$
G=(V, E, R)
$$


where $V$ is specified of graph peaks, $E$ is specified of graph edges, and $R$ is specified of drop relationships.

Thus, a graph $G$ comprises a firm of non-empty elements called vertices; a firm of pairs connected by a firm of vertices called edges; and established vertices named edges; and confirmed direction functions[10].

A set consisting of vertices of a graph $G$ is called the set of vertices of a graph and is denoted by $V(G)$. Similarly, a set consisting of edges is called the set of edges and is denoted by $E(G)$. If $v_{i}$ and $v_{j}$ are vertices of the graph $G$, then the edge of $v_{I} v_{j}$ is called the connection that connects $v_{i}$ and $v_{j}$.

Two vertices $v_{i}$ and $v_{j}$ are boundary vertices of an edge $e$ if $v_{i}$ is the beginning of the edge and $v_{j}$ is the end of the edge. Two vertices $v_{i}$ and $v_{j}$ are adjacent if they are distinct and exist, and there is an edge running from one of them to the other. It is assumed that an edge $e$ comes from vertex $v_{i}$ if $v_{i}$ is the beginning but not the end of $e$, and that an edge goes to $v_{i}$ if $v_{i}$ is the end but not the beginning of $e$. In both cases, the edge $e$ is called the incident vertex $v_{i}$, and the vertex $v_{i}$ is called the incident edge $e$. The total number of edges incident to vertex $v_{i}$ is a power of vertex $v_{i}$ and is denoted $b\left(v_{i}\right)$.

THE MATRIX FORM OF PRESENTATION OF THE DOCUMENT MANAGEMENT OF TECHNICAL DOCUMENTATION

To represent the workflow of technical documentation, it is advisable to use the matrix form $[15,16]$. The matrix form uses three sets from the previously introduced triple $\{Y, P$, $F\}$.

Packages are considered updated at the time of submission, i.e. all states are represented by many forms, all actions that lead to a change of situation are represented by many actions, and production stages in the shape of roles for many participants. The grid model is the current condition of the project documentation workflow that works with a limited number of engineering design.

To solve the above problem, it is offered to use a set of square matrices of work sequences, every one that illustrates the process state in a discrete exact unit of time. The columns in the workflow matrix are set according to the document conditions that may occur during the workflow's life cycle.

That is, the first column corresponds to the first element of based $F$, the second column the second element and so on, until the previous element based $F$. the rows of the paper patterns are process-related, producing at least one leads to a change in the status of the document. The first row corresponds to the first element based $P$, the second row to the second, and so on, for the entire basis $P$.

Thus, rectangles are obtained with matrix columns, the number of which is equal to the dimension of the basis $F$ and rows in the dimension of the matrix $P$. this model is covered with items of the set of role participants in the construction of documents circulation $Y$.

If the row action does not change the column state at this workflow step, the matrix element is filled with empty or null values. The criterion for the success of creating a matrix is its non-degeneracy in columns and rows. In other words, there is at least one column in the matrix that contains a non-empty element and at least one row that contains a nonempty element. However, it is assumed that not all elements of the set of role participants in $Y$ will be used for filling in.

Thus, a matrix of technical documentation workflow is obtained, the content of which uniquely corresponds to the state of document flow at the first step. After the first event occurs, after the first action occurred, a change in at least one state will be updated the workflow matrix. Namely, the matrix content will be brought in such a way that the matrix elements correspond to the current state - the second step of document flow. Thus, at the second step, get a matrix filled in by the participants of this step, who are at the intersection of the actions they perform and the States that these actions change. 
The number of steps in a workflow can be large, but it can still be limited because the workflow itself can be thought of as a limited set of matrices described above. Every matrix reflects the general state of the entire executive process of the master document at a time when there are no changes in the document states.

\section{Results and Discussion}

\section{GRAPH-BASED WORKFLOW MODEL.}

To illustrate the meaningful meaning of the concepts used will be considered a document flow model based on the proposed graph model.

As a basis, will be considered the General technological method of maintaining custom specifications (MCS) for railway automation and telemechanics (Figure. 1), presented in the article [17].

The process consists of the following steps:

1) the Project organization makes custom specifications (CS) based on the completed project for the objects under construction or reconstruction.

2) The compiled CS is approved by the automation and telemechanics service.

3) following, the CS is sent to the major construction section (MCS). This information is used to detect which apparatus producers require ordering. Since there are several hundred items of equipment and devices in the CS, the probability that only one factory produces them is very small. MCS divides the equipment specified in the CS between suppliers.

4) Suppliers, in turn, give an order to the factory to complete the order.

5) at the end of the work, the plant sends the equipment to the warehouse signaling distance.

Will be considered the General technological process of technical characteristics CS of railway automation and telemechanics (Figure 1), given in [18].

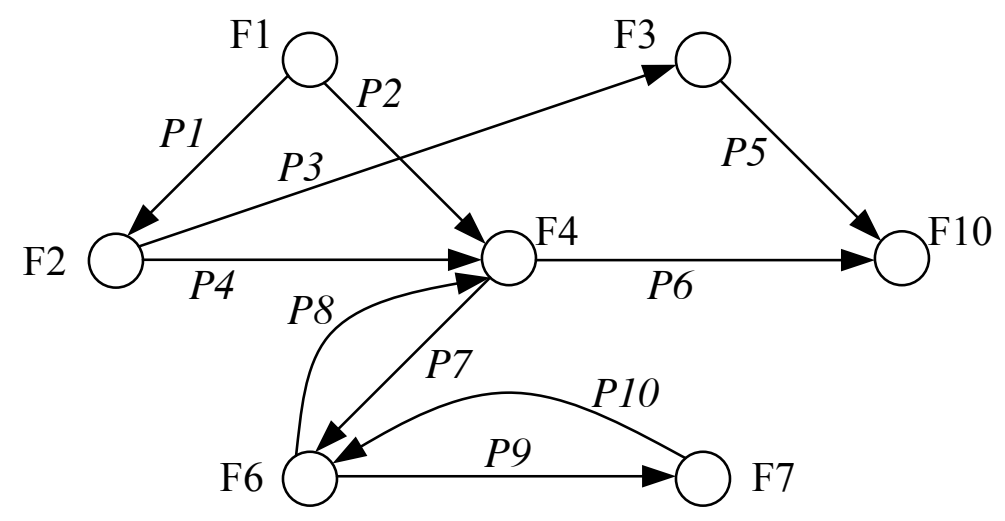

Fig.1. Graph of the technological process for maintaining specifications of railway automation and telemechanics

The following notation is used to set model parameters:

documents are indicated by a set of forms used in the modeled process. Note these forms $F 1$...F 10 .

the process performed by documents that change States is defined by a set of processes $P 1$...P10.

performing processes $P 1 \ldots P 10$, are denoted by the set $Y 1 \ldots Y 10$. 
Possible scenarios for the process of maintaining custom specifications that a given model can implement will be considered. For this, a table in the form of a matrix (table 1) and possible transitions of the VSS process will be shown (table 2).

From table 1, definition of the set $\mathrm{Y}$ :

$\mathrm{Y} 1=\mathrm{P} 2 \mathrm{~F} 4 \mathrm{VP} 1 \mathrm{~F} 2$

$\mathrm{Y} 2=\mathrm{P} 1 \mathrm{~F} 2 \vee \mathrm{P} 3 \mathrm{~F} 4 \vee \mathrm{P} 4 \mathrm{~F} 3$

$\mathrm{Y} 3=\mathrm{P} 4 \mathrm{~F} 3 \vee \mathrm{P} 5 \mathrm{~F} 10$

$\mathrm{Y} 4=\mathrm{P} 2 \mathrm{~F} 4 \vee \mathrm{P} 6 \mathrm{~F} 6 \vee \mathrm{P} 9 \mathrm{~F} 4 \vee \mathrm{P} 3 \mathrm{~F} 4 \vee \mathrm{P} 4 \mathrm{~F} 10$

$\mathrm{Y} 6=\mathrm{P} 6 \mathrm{~F} 6 \vee \mathrm{P} 9 \mathrm{~F} 4 \vee \mathrm{P} 7 \mathrm{~F} 7 \vee \mathrm{P} 8 \mathrm{~F} 6$

$\mathrm{Y} 7=\mathrm{P} 7 \mathrm{~F} 7 \mathrm{VP} 8 \mathrm{~F} 6$

$\mathrm{Y} 10=\mathrm{P} 5 \mathrm{~F} 10 \vee \mathrm{P} 4 \mathrm{~F} 10$

Table 1. Matrix table (Y, P, F) for the MCS process

\begin{tabular}{|c|c|c|c|c|c|c|c|c|c|c|}
\hline$F$ & $F 1$ & $F 2$ & $F 3$ & $F 4$ & $F 5$ & F6 & $F 7$ & $F 8$ & $F 9$ & $F 10$ \\
\hline$P 1$ & Y1 & $\begin{array}{l}\text { Y1 } \\
\text { Y2 }\end{array}$ & & & & & & & & \\
\hline$P 2$ & & & & $\begin{array}{l}\text { Y1 } \\
\text { Y4 }\end{array}$ & & & & & & \\
\hline$P 3$ & & & & $\begin{array}{l}\text { Y2 } \\
\text { Y4 }\end{array}$ & & & & & & \\
\hline$P 4$ & & & $\begin{array}{l}\mathrm{Y} 2 \\
\mathrm{Y} 3 \\
\end{array}$ & & & & & & & \\
\hline$P 5$ & & & & & & & & & & $\begin{array}{c}\mathrm{Y3} \\
\mathrm{Y} 10 \\
\end{array}$ \\
\hline P6 & & & & & & $\begin{array}{l}\text { Y4 } \\
\text { Y6 } \\
\end{array}$ & & & & \\
\hline$P 7$ & & & & & & & $\begin{array}{l}\text { Y6 } \\
\text { Y7 } \\
\end{array}$ & & & \\
\hline$P 8$ & & & & & & $\begin{array}{l}\text { Y7 } \\
\text { Y6 }\end{array}$ & & & & \\
\hline$P 9$ & & & & $\begin{array}{l}\text { Y6 } \\
\text { Y4 }\end{array}$ & & & & & & \\
\hline$P 10$ & & & & & & & & & & $\begin{array}{c}\text { Y4 } \\
\text { Y10 }\end{array}$ \\
\hline
\end{tabular}

Table 2. Table of possible transitions of the MCS process.

\begin{tabular}{|c|c|c|c|c|c|c|c|c|c|c|c|c|}
\hline$\#$ & P & F & Y1 & Y2 & Y3 & Y4 & Y5 & Y6 & Y7 & Y8 & Y9 & Y10 \\
\hline 1 & P2 & F4 & 1 & & & 1 & & & & & & \\
\hline 2 & F6 & F6 & & & & 1 & & 1 & & & & \\
\hline 3 & P9 & F4 & & & & 1 & & 1 & & & & \\
\hline 4 & P7 & F7 & & & & & & 1 & 1 & & & \\
\hline 5 & P8 & F6 & & & & & & 1 & 1 & & & \\
\hline 6 & P1 & F2 & 1 & 1 & & & & & & & & \\
\hline 7 & P3 & F4 & & 1 & & 1 & & & & & & \\
\hline 8 & P4 & F3 & & 1 & 1 & & & & & & & \\
\hline 9 & P5 & F10 & & & 1 & & & & & & & 1 \\
\hline 1 & P4 & F10 & & & & 1 & & & & & & 1 \\
0 & F & & & & 1 & & & & & & 1 \\
\hline
\end{tabular}

From the set $\mathrm{Y}$, those that have the same elements are combined:

$\mathrm{Y} 6=\mathrm{P} 6 \mathrm{~F} 6 \vee \mathrm{P} 9 \mathrm{~F} 4 \vee \mathrm{Y} 7$ 
Will be applied chart concept terminology to the workflow type of project documentation. Then the probable workflow schemes correspond to the graphical paths (Figure 2).

In the presented graph, there are five possible paths, which are denoted by edges.

\begin{tabular}{|c|c|c|c|c|c|c|c|c|c|c|}
\hline$P / F$ & $F 1$ & $F 2$ & $F 3$ & $F 4$ & $F 5$ & F6 & $F 7$ & $F 8$ & $F 9$ & $F 10$ \\
\hline$P 1$ & & & & & & & & & & \\
\hline$P 2$ & & & & & & & & & & \\
\hline$P 3$ & & & & & & & & & & \\
\hline$P 4$ & & & $Y_{2,3}$ & & & & & & & \\
\hline$P 5$ & & & & & & & & & & $\rightarrow Y_{3,10}$ \\
\hline$P 6$ & & & & & & & & & & \\
\hline$P 7$ & & & & & & & & & & \\
\hline$P 8$ & & & & & 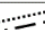 & $\mathbf{Y}_{7,6}$ & & & & \\
\hline$P 9$ & & & & $\mathbf{Y}_{9,4}$ & - & & & & 4 & \\
\hline$P 10$ & & & & & & & $\cdots$ & N.:-1. & ㄱ.:- & $\mathbf{Y}_{10,10}$ \\
\hline$\bullet \longrightarrow$ & Sce & ario 1 & & & & & & & & \\
\hline - …… & Sce & ario 2 & & & & & & & & \\
\hline$a-\rightarrow$ & Sce & ario 3 & & & & & & & & \\
\hline$\bullet \rightarrow \rightarrow$ & Sce & ario 4 & & & & & & & & \\
\hline$\bullet \cdots \cdots$ & $\mathrm{Sc}$ & ario 5 & & & & & & & & \\
\hline
\end{tabular}

Fig.2. Graphic transitions of the technological process of maintaining the technical characteristics of railway automation and telemechanics systems.

These paths correspond to the scenarios MCS.

Will be imagined the EDTD patterns corresponding to the considered scenarios. At every stage of the script, a workflow step is performed that corresponds to the work being done on the documents.

Scenario 1. at stage 1, the elements of the source P1, F1 and P1, F2 get the values Y1 and Y2 (Fig. 2). At stage 2, the source elements P1, F2 and P4, F3 get the values Y2 and Y3, and at stage 3, the elements P4, F3 and P5, F10 sequentially get the rates Y3 and Y10.

Scenario 2. At stage 1, the matrix elements P1, F1 and P2, F4 get the rates Y1 and Y4, sequentially. At stage 2, the matrix elements P2, F4 and P10, F10, respectively, get the values $\mathrm{Y} 4$ and $\mathrm{Y} 10$.

Scenario 3. at stage 1, the matrix elements P1, F1 and P1, F2 get the values Y1 and Y2. At stage 2, the matrix elements P1, F2 and P3, F4 get the values Y2 and Y4, and at stage 3, the elements P3, F4 and P10, F10 sequentially get the rates Y4 and Y10.

Scenario 4. at stage 1, the matrix elements P1, F1 and P1, F2 get the rates $\mathrm{Y} 1$ and $\mathrm{Y} 2$. In step 2, the matrix elements P1, F2 and P3, F4 to get the rates Y2 and Y4, for phase 3 elements $\mathrm{P} 3, \mathrm{~F} 4$ and $\mathrm{P} 6, \mathrm{~F} 6$ sequentially receive the rates of $\mathrm{Y} 4$ and $\mathrm{Y} 6$, in step 4, the elements P6, F6 and P7, F7 sequentially receive the rates of Y6 and Y7, in step 5 the elements P7, F6 and P8, F6 sequentially receive the rates of $\mathrm{Y} 7$ and Y6, and in step 6 the elements of P8, F6 and P9, F4 sequentially receive the rates of Y6 and Y4, in step 7, the elements $\mathrm{P} 9, \mathrm{~F} 4$ and $\mathrm{P} 10, \mathrm{~F} 10$ sequentially receive the rates of Y4 and Y10.

Scenario 5. At stage 1, the matrix elements P1, F1 and P2, F4 get the rates Y1 and Y4, sequentially. In step 2, the elements of the matrix P2,F4 and P6,F6 sequentially receive the rates of $\mathrm{Y} 4$ and $\mathrm{Y} 6$, stage 3 elements $\mathrm{Y} 6$, $\mathrm{Y} 7$ and $\mathrm{P} 6, \mathrm{~F} 6$ sequentially receive the rates of $\mathrm{Y} 6$ and $\mathrm{Y} 7$, the stage 4 elements P7, F7 and P8, F6 sequentially receive the rates of $\mathrm{Y} 7$ and $\mathrm{Y} 6$, in step 5 the elements of P8,F6 and P9, F4 sequentially receive the rates of Y6 and Y4, in step 6 the elements of P9,F4 and P10,F10 sequentially receive the rates of Y4 and Y10.

Consequently, event patterns discover the type of the EDTD chart of the represented proceeding.

The basis of patterns specified above bases whole probable schemes of the flow of document in the proceeding, illustrate whole probable cases of document flow (Fig. 3) and defines conceivable members. 


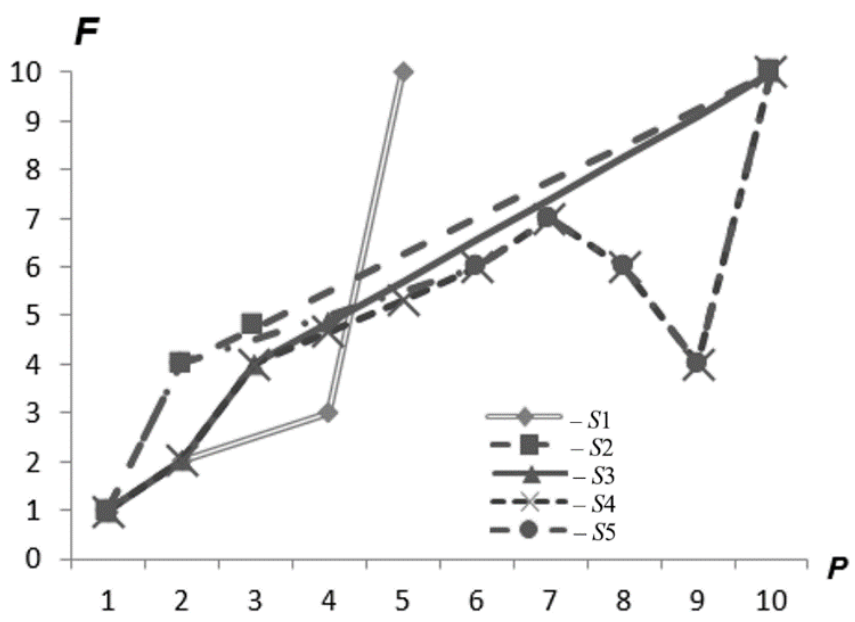

Fig.3. Graph of modifications in the state of the MCS method.

In addition to the mapping matrix, it is convenient to display the graph by the contiguity matrix. Just as the matching matrix reflects the relationship between the ends and edges, the contiguity matrix ends reflect the relationship between each other. In the proposed model, the contiguity matrix reflects the relationship of States (Figure. 4). the elements include actions that lead to changes in States.

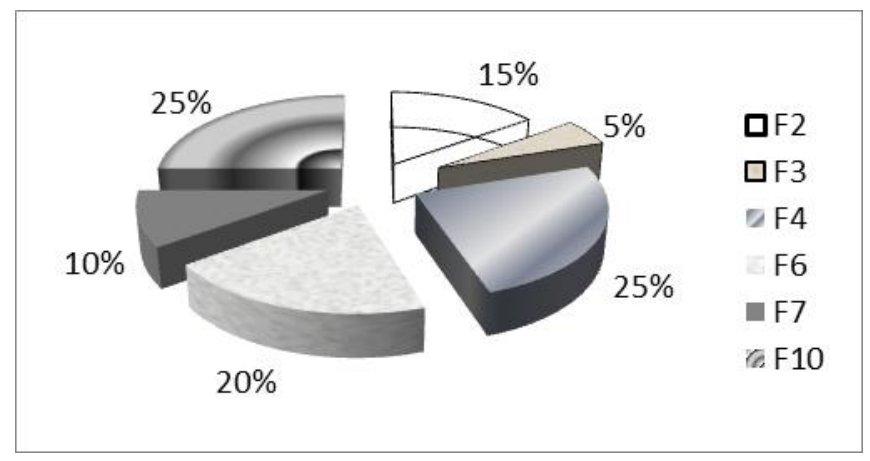

Fig. 4. Graphic process of the ratio of condition of the MCS.

Build the methodology for establishing a theoretical type of flow of documents systems for technical documentation [5] and a composite flow of documentation [10]; this article presents a chart type of electronic document management for technical documentation, which takes into account the decomposition of work flows into a set of process participants, a basis of States, and a basis of actions.

\section{Conclusions}

A graphical form of electronic document flow of technical documents has been synthesized through formalized methods of analysis, synthesis and study of the electronic document management of technical documents. The developed model takes into account the division of document flows into a set of participants, processes and situations. It is recommended to use a set of matrices to determine the form of presentation of the workflow of technical documentation. A method of creating an electronic document flow model of technical documents based on the apparatus of graph theory has been developed. 
The result:

- Creation, control of the process of electronic maintenance of technical documentation of automation and telemechanics devices and the study of their actual operation;

- the advantages of documentation processes and features of technical documentation are identified;

- developed a method of creating a system of the electronic document management of technical documents based on theory through a graphical system;

- It is proposed to use a rectangular matrix to show the working process of technical documentation;

- Methods for determining all data for this system are shown, and algebra of technical document flow through graphs is proposed.

In summary, a formalized algorithms and control system for railway automation and telemechanics devices, a description of automated accounting and control systems, components of the electronic executive part of the system, a manual on the use of automated systems in the control of automation and telemechanics devices.

\section{References}

1. Bulavsky P E, Conceptual model of electronic document management of technical documentation (Transport of the Russian Federation) 1 (32) p. 60-63. (2011)

2. Vasilenko M N, Trohov V G, Zuev D V, Electronic document management in railway signalling (Automation communication Informatics) p. 2-3. (2014).

3. Vasilenko M N, Trohov V G, Zuev D V, The development of electronic document management in railway automation and telemechamics, (Automation communication Informatics) p. 14-16, (2015).

4. Bulavsky P E, Markov D S, Electronic document management of technical documentation, Automation communication Informatics №2 p. 2-4. (2012).

5. Baratov D Kh, Boltaev A Kh, Astanaliev E T, Functional Support of the Automated Accounting System and Control of Devices in Railway Automation Telemechanics, International Journal of Advanced Research in Science Engineering and Technology, 6 (3) p.8572-8580. (2019).

6. Aripov N M, Baratov D Kh, About document management in the Department of automation and telemechanics and the introduction of paperless technology technical documentation management (Bulletin of the Tashkent Railway Transport Engineering Institute) p.77-81. (2015).

7. Krukovsky M Y, The Graph model of composite workflow Mathematical machines and machine systems, (3) p. 149-163. (2005)

8. Diestel R, Graph Theory Electronic Edition. p. 422. (2005)

9. Zykov A A, Fundamentals of graph theory, (University book) p. 664. (2004).

10. Domnin L N, Elements of graph theory, (Penza Publishing house Penza state University). p. 144. (2007)

11. Bulavsky P E, Markov D S, Matrix method of formalization of simulation models of complex queuing systems (proceedings of PGUPS), (4) p. 186-195. (2010)

12. Bulavsky P E, Markov D S, Hierarchical multi formalization of a simulation model of electronic document management of technical documentation Topical issues of development of systems of railway automatics and telemechanics (collection of scientific works PGUPS) p. 52-59. (2013).

13. Baratov D Kh, Aripov N M, Ruziev D Kh, Formalized Methods of Analysis and Synthesis of Electronic Document Management of Technical Documentation (In 2019 IEEE East-West Design \& Test Symposium EWDT)) p. 1-9 
14. Dilshod Baratov, Elmurod Astanaliev, Using innovative technologies of electronic technical document management for railway automation and telemechanics International Engineering Journal for Research and Development, (5) p. 5-9. (2020).

15. Dilshod Baratov, Elmurod Astanaliev, Using innovative technologies of electronic technical document management for railway automation and telemechanics, International Journal on Orange Technologies IJOT 3 (1) ISSN: 2615-7071 p. 7-10 (2021).

16. Wilkes M V, Stringer J B, Micro-programming and the design of the control circuits in an electronic digital computer, Mathematical Proceedings of the Cambridge Philosophical Society (Cambridge University Press 49) p. 230-238. (2008)

17. Aguilar A, Lozoya C, Orona L M, A hamming distance and fuzzy logic-based algorithm for P2P content distribution in enterprise networks, Peer-to-Peer Networking and Applications 12(5) p. 1323-1335 (2019).

18. Furth S Baumeister J, Semantification of large corpora of technical documentation. In Enterprise Big Data Engineering Analytics and Management p. 171-200. (2016).

19. Yatin S F, Ramli A A, Shuhaimi H, Hashim H, Electronic Document Management System, Malaysian Experience Australian Journal of Basic and Applied Sciences 9 (3) p. 82-89. (2015).

20. Sun M T, Hou J L, The architecture and models for document security reasoning in an electronic document management system, Journal of the Chinese Institute of Industrial Engineers 20 (4) p. 305-316, (2003).

21. Sokolov S S, Karpina A S, Gaskarov V D, Methods and models of designing the secure system of electronic document management in transport logistic cluster, Bulletin of Astrakhan State Technical University (Management Computer Sciences and Informatics) p. 40-52. (2016).

22. Guo F, Jahren C T, Turkan Y, Electronic Document Management Systems for the Transportation Construction Industry International Journal of Construction Education and Research p 1-16 (2019)

23. Shamanov V, Generalized mathematical model of the process of operating automation systems and telemechanics (Automation on Transport 2) p. 163-179. (2016) 